\title{
Da Nova República à nova direita: 0 bolsonarismo como sintoma mórbido
}

\section{From New Republic to new right: bolsonarism as a morbid symptom}

\section{De la Nueva República a la nueva derecha: el bolsonarismo como síntoma mórbido}

iD Ivan Henrique de Mattos e Silva

Universidade Federal do Amapá, Macapá, Amapá, Brasil ivansilva@unifap.br

Resumo: O presente trabalho está centrado em uma discussão a respeito da crise da Nova República no Brasil - tanto do ponto de vista institucional quanto de suas balizas orgânicas e ideológicas -, bem como da ascensão de novos grupos políticos nas primeiras décadas do século XXI abertamente identificados com uma direita reinventada, que encontraram na eleição de Jair Bolsonaro para a Presidência da República, em 2018, o desaguadouro institucional de uma longa disputa ideológica no seio da sociedade civil operada como guerra de posições. O argumento central desta reflexão reside na categorização da crise da Nova República como uma crise de hegemonia, e, portanto, do próprio pacto social de dominação política construído durante o processo de redemocratização das décadas de 1980 e 1990. Imerso em um interregno, o Brasil teria, no bolsonarismo, o principal sintoma dessa paralisia histórica.

Palavras-chave: Nova República. Nova Direita. Bolsonarismo. Crise de Hegemonia. Interregno.

Abstract: The present work is centered on a discussion about the crisis of the New Republic in Brazil - both from an institutional point of view and from its organic and ideological foundations - as well as the rise 
of new political groups in the first decades of the 21st century openly identified with a reinvented right, which found in the election of Jair Bolsonaro to the Presidency of the Republic in 2018 the institutional outlet of a long ideological dispute within civil society operated as a war of position. The central argument of this reflection resides in the categorization of the crisis of the New Republic as a crisis of hegemony, and, therefore, of the social pact of political domination built during the process of redemocratization of the 1980s and the 1990s. Immersed in an interregnum, Brazil would have, in Bolsonarism, the main symptom of this historical paralysis.

Keywords: New Republic. New Right. Bolsonarism. Crisis of Hegemony. Interregnum.

Resumen: El presente trabajo se centra en una discusión sobre la crisis de la Nueva República en Brasil - tanto desde el punto de vista institucional como de sus lineamientos orgánicos e ideológicos - así como el surgimiento de nuevos grupos políticos en las primeras décadas del siglo XXI abiertamente. identificados con una derecha reinventada, que encontró en la elección de Jair Bolsonaro para la Presidencia de la República, en 2018, la concretización institucional de una larga disputa ideológica dentro de la sociedad civil operada como una guerra de posiciones. El argumento central de esta reflexión reside en la categorización de la crisis de la Nueva República como crisis de hegemonía y, por lo tanto, del pacto social de dominación política construido durante el proceso de redemocratización de las décadas de 1980 y 1990. Inmerso en un interregno, Brasil tendría, en el bolsonarismo, el síntoma principal de esta parálisis histórica.

Palabras clave: Nueva República. Nueva Derecha. Bolsonarismo. Crisis de Hegemonía. Interregno.

Data de recebimento: 25/02/2021

Data de aprovação: 22/06/2021 
Da Nova República à nova direita: o bolsonarismo como sintoma mórbido

\section{Introdução}

Após 27 anos de política parlamentar de nicho - em larga medida restrita à defesa corporativa dos interesses profissionais e monetários dos militares -, cultivando a estética e a retórica de uma caricatura do chamado baixo clero do Legislativo brasileiro, o então deputado Jair Messias Bolsonaro saltou, em 2018, da absoluta irrelevância parlamentar diretamente para o Palácio do Planalto, em uma eleição que se apresentou - para parafrasear a clássica reflexão de Marx (2006) a respeito do golpe de Estado na França em 1851 - como raio em céu azul. Junto com ele, assumiram a centralidade da agenda pública brasileira o negacionismo científico, o conspiracionismo e um anticomunismo ao mesmo tempo anacrônico e caricato, aliados a uma explosão de candidaturas de membros das Forças Armadas e das corporações policiais (inclusive da ativa) e a um expressivo aumento da participação de militares em funções de Estado, mesmo em comparação à ditadura militar brasileira (1964-1985) (LEIRNER, 2020).

Segundo dossiê produzido pelo Sindicato Nacional dos Docentes das Instituições de Ensino Superior (ANDES-SN), entre 2016 e 2021 houve um crescimento de 108,22\% na participação de militares da ativa e da reserva em cargos do serviço público civil (OHANA, 2021). Ademais, com oito ministros militares num conjunto de 22 ministérios (no ano de 2020), o governo Bolsonaro alcançou um número superior a três presidentes da ditadura militar (Médici, Geisel e Figueiredo) e empatou com o governo Costa e Silva (BARRUCHO, 2020). A aparência repentina desse salto esconde, todavia, um profundo processo de reordenamento político e ideológico no país. Ou seja, havia nuvens carregadas por trás do azul do céu.

Argumenta-se, neste texto, que a ascensão de uma nova direita no Brasil - da qual Jair Bolsonaro se converteu em principal expressão institucional - é um subproduto imediato da crise estrutural da Nova República, e que, portanto, as raízes desse processo 
Da Nova República à nova direita: o bolsonarismo como sintoma mórbido Ivan Henrique de Mattos e Silva

se encontram nos próprios fundamentos da corrosão do pacto sociopolítico costurado durante a reconstrução democrática entre as décadas de 1980 e 1990. A hipótese sustentada aqui é que a crise da Nova República não deve ser definida como simplesmente uma crise política, institucional, ou mesmo econômica, mas como crise de hegemonia, de modo que o período inaugurado pela destituição da Presidenta Dilma Rousseff, em 2016, e aprofundado pela eleição de Jair Bolsonaro, em 2018, é um interregno, do qual o bolsonarismo, por sua vez, é seu principal sintoma mórbido.

A análise empreendida neste texto está estruturada na forma de um ensaio e busca sustentar essa hipótese a partir de uma reconstrução histórica da trajetória de surgimento, consolidação e ocaso da Nova República enquanto nova hegemonia, que teve, no "momento maquiaveliano" representado pela eleição do presidente Fernando Henrique Cardoso (em 1994), o seu episódio inaugural e, nos movimentos de junho de 2013 , a manifestação sintomática mais aguda de sua crise orgânica enquanto pacto social e político de dominação. Como um ensaio, o esforço de sustentação da hipótese se apoiará na mobilização de argumentos em torno de processos políticos e sociais brasileiros ao longo das últimas décadas, concatenados e sistematizados a partir de uma cadência lógica.

\section{Crise de Estado, redemocratização e Nova República}

A crise que se manifesta no Brasil durante a década de 1980 representa o esgotamento não apenas do modelo nacional-desenvolvimentista de um ponto de vista estritamente econômico, mas, sobretudo, do próprio pacto social que sustentou o projeto de modernização no Brasil ao longo de boa parte do século XX e de modo mais acentuado ao longo das décadas de 1950, 1960 e 1970. Assim, o desarranjo entre Estado, capital internacional, capital nacional e parcelas organizadas da classe trabalhadora urbana (fragilizadas e golpeadas durante a ditadura militar) condicionou o ocaso do nacional-desenvolvimentismo brasileiro como 
Da Nova República à nova direita: o bolsonarismo como sintoma mórbido Ivan Henrique de Mattos e Silva

uma crise não apenas econômica, mas de hegemonia' ${ }^{1}$, ou seja, de seus próprios fundamentos sociais, políticos e ideológicos ${ }^{2}$. A transição brasileira, portanto, não pode ser compreendida como simplesmente uma mudança de forma política (MASCARO, 2015), mas como repactuação social.

Embora o processo constituinte de 1987-1988 seja um claro divisor de águas na trajetória de reconstrução da democracia brasileira, ele não resume, em si, a superação da crise de hegemonia dos anos 1980. Essa reflexão parte da tese de Brasilio Sallum Jr., que sustenta que a transição brasileira só se concretiza em meados da década de 1990, a partir da conjugação de dois fatos políticos de grande magnitude - o Plano Real e a eleição do presidente Fernando Henrique Cardoso:

\begin{abstract}
A transição política brasileira começou com a crise de Estado de 1983-1984 e terminou com o primeiro governo de Fernando Henrique Cardoso, momento em que o Estado ganhou estabilidade segundo um novo padrão hegemônico de dominação, moderadamente liberal em assuntos econômicos e completamente identificado com a democracia representativa (SALLUM JR., 2003, p. 35-36).
\end{abstract}

A transição brasileira enseja, portanto, mais do que uma metamorfose de regime, um metabolismo do Estado - ou seja, não apenas uma alteração em sua forma, mas em seu conteúdo: há uma mudança profunda no modelo de Estado construído no Brasil desde o início do século XX (SALLUM JR., 1994). Durante os anos 1980, a América Latina passa por um profundo processo de reorganização das relações entre poder político, sociedade e mercado e a forma de inserção internacional das economias nacionais - cujo pano de fundo ideológico é um contexto internacional marcado retoricamente pela associação estratégica entre democracia e li-

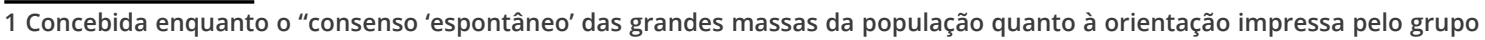
fundamental dominante" (GRAMSCl, 1980, p. 14).

2 Ideologia, na chave gramsciana, é uma concepção de mundo que se manifesta em todas as expressões da vida individual e coletiva, uma força ativamente organizadora no sentido de moldar o terreno no qual os indivíduos atuam e lutam (GRAMSCl, 1991; EAGLETON, 2019).
} 
Da Nova República à nova direita: o bolsonarismo como sintoma mórbido

beralização econômica como o fundamento da modernidade contemporânea (SALLUM JR., 1999), como se democracia e ortodoxia de mercado fossem as duas faces da mesma moeda: a feição mais contemporânea da marcha civilizatória (SALLUM JR., 2004). A crise fiscal dos países latino-americanos é a manifestação mais dramática e aguda de uma série de desarranjos políticos, econômicos e sociais, e, no caso brasileiro, da corrosão do próprio pacto social que pavimentou nossa via prussiana de desenvolvimento, afetando de modo direto o endosso da classe média à ditadura militar e, lato sensu, ao próprio Estado desenvolvimentista (SALLUM JR., 1996).

Malgrado a tentativa de reeditar um pacto desenvolvimentista - sem, todavia, o devido lastro material -, a Assembleia Nacional Constituinte não encerrou a superação da paralisia histórica representada pela crise de Estado: embora o processo constituinte tenha sido um momento fundamental nessa trajetória, é apenas com a costura institucional, política e ideológica - conduzida por elites políticas e econômicas no seio do Estado brasileiro -, que desemboca no Plano Real e na eleição de Fernando Henrique Cardoso para a Presidência da República, que se tornou possível o estabelecimento dos marcos de uma nova hegemonia sustentada pela articulação entre partidos de centro-direita e da direita tradicional (cujas maiores expressões foram, respectivamente, o PSDB e o PFL) em torno da continuidade das reformas neoliberais ensaiadas durante o governo Collor (1990-1992) aliadas a políticas compensatórias (SALLUM JR., 1999). No âmbito de uma conjuntura internacional que associou estrategicamente democratização da política e liberalização da economia, as elites brasileiras tiveram virtù para, num "momento maquiaveliano", configurar um novo pacto social hegemônico e, assim, finalizar a transição brasileira (SALLUM JR., 1999, 2003):

A oscilação catastrófica entre os extremos do travamento pemedebista e o cesarismo alucinado de Collor, a ameaça de uma vitória de Lula em 1994 e certo consenso da elite política de que 
Da Nova República à nova direita: o bolsonarismo como sintoma mórbido

era necessário produzir um ajuste profundo no modelo de sociedade, tudo isso estabeleceu as bases para o surgimento de um novo pacto político representado pelo Plano Real (NOBRE, 2013, p. 61-62).

O rearranjo institucional operado na reconstrução democrática produziu três fenômenos significativos: um sistema partidário relativamente estável, capitaneado por duas forças oriundas da luta pela redemocratização - uma de centro-direita e outra de centro-esquerda; a estruturação de um binômio normativo, que se configurou como pilar estruturante da nova hegemonia brasileira; e a consolidação de um consenso mínimo quanto aos valores e ao campo semântico normatizados na esfera pública.

A reestruturação social e política construída na esteira do processo eleitoral de 1994 condiciona a criação de um cenário político bipolar no Brasil, colocando o PMDB no centro (tanto de um ponto de vista razoavelmente ideológico, como, mais especificamente, estratégico) de um contínuo partidário que possuía como os dois principais atores o PSDB, de um lado, e o PT, de outro (NOBRE, 2013). Para além da configuração de um esboço de estrutura bipartidária - considerando apenas as disputas pelo Executivo Nacional -, a repactuação social que consolida a Nova República no Brasil enseja também a constituição de uma nova hegemonia que se sustenta em um binômio estratégico e, ao mesmo tempo, contraditório: uma macroeconomia ortodoxa, por um lado, e a defesa de políticas de redução de assimetrias (sociais, políticas, econômicas e simbólicas), por outro (SALLUM JR., 1999; SOLA, KUGELMAS, 1996; SILVA, 2018). Em outras palavras, o binômio representa a complexa articulação entre os interesses imediatos das frações burguesas vinculadas ao capital financeiro e as demandas reprimidas ao longo de décadas de modernização conservadora por uma participação minimamente mais equânime nos frutos do progresso social.

Em relação ao consenso mínimo em torno de um léxico político mais inclusivo, a Nova República parece ser a manifestação brasi- 
Da Nova República à nova direita: o bolsonarismo como sintoma mórbido Ivan Henrique de Mattos e Silva

leira de um fenômeno mundial que se inicia em meados dos anos 1960, marcado pela intensificação de um processo de subjetivação nucleado no conceito de tolerância - com forte apoio no pluralismo liberal -, e capitaneado tanto por uma nova esquerda, que buscava se afastar das experiências do chamado socialismo real, como por movimentos sociais emergentes, ONGs, academia e grandes empresas (BURITY, 2018). A subjetivação nucleada no conceito de tolerância - cujo desaguadouro no caso brasileiro é a repactuação social da Nova República - ensejou um relativo consenso em relação ao conjunto de valores que tinham guarida na esfera pública: a defesa, mais ou menos genérica, da inclusão como valor universal; o reconhecimento da multiplicidade de expressões culturais, étnicas, sexuais e de gênero; e a consolidação da democracia (ainda que na chave competitiva) como forma política por excelência. A esse campo semântico relativamente consensual foi dado o nome de "politicamente correto" (DI CARLO; KAMRADT, 2018).

O ocaso da Nova República e a consequente ascensão de uma nova direita no Brasil passam, necessariamente, pela desconstrução desses fundamentos, tanto materiais como simbólicos, fruto de uma concatenação de fatores nacionais e internacionais. A próxima seção se dedica a esmiuçar esse processo.

\section{A crise de hegemonia da Nova República em sete movimentos}

Há sete movimentos razoavelmente articulados que ajudam a explicar o processo de corrosão dos fundamentos do pacto social pós-redemocratização no Brasil: o ativismo judicial, a politização dos quartéis, a crise da centro-direita, a crise da sociabilidade neoliberal, as revoltas do precariado, a ascensão política do neopentecostalismo e, em especial, a ascensão da nova direita (desaguadouro dos seis movimentos anteriores). A conjunção desses movimentos - que atacam o núcleo duro do modelo político que começa a se construir no Brasil ainda no processo de redemo- 
Da Nova República à nova direita: o bolsonarismo como sintoma mórbido

cratização (PINHEIRO-MACHADO; FREIXO, 2019) - compõe o figurino do processo de esgotamento da Nova República. E é nesse contexto de esgotamento (que não se limita ao arranjo político e social brasileiro) - aqui chamado de interregno - que se insere o crescimento avassalador do neoconservadorismo em suas várias vertentes. Para além do caso brasileiro, a ascensão da extrema-direita no século XXI é o subproduto imediato de uma era marcada pelo ocaso das utopias (BIANCHI; MELO, 2018), inclusive a utopia da democracia representativa como conquista civilizatória definitiva do liberalismo.

O ativismo judicial (primeiro movimento da corrosão do pacto social da Nova República) diz respeito a dois fenômenos distintos: a judicialização da política, por um lado, e a politização da justiça, por outro. Sem negligenciar as distinções e os meandros dessa dupla conceituação - como presente nas análises de Werneck, Burgos e Salles (2007), Hirschl (2009) e Avritzer e Marona (2014) -, interessa, para o raciocínio desenvolvido aqui, considerar o ativismo judicial como uma lógica de paulatina assunção, por parte do Poder Judiciário no Brasil (em várias instâncias), da tarefa de novo demiurgo político, ora imbuído da função de ser a ponta de lança de um processo de depuração moral da política institucional brasileira, ora imbuído de um objetivo manifesto de refundação da República.

Embora possua raízes mais longas (WERNECK; BURGOS; SALLES, 2007), o apogeu da manifestação sintomática e sistêmica do ativismo judicial no país é inaugurado pelo julgamento da Ação Penal 470 (o Mensalão), e encontra seu desaguadouro na constituição da Operação Lava Jato em uma instituição em si, com agenda, recursos e interesses próprios. Em ambos os casos, a hiperexposição midiática forneceu um importante instrumento à agenda de flexibilização das normas jurídicas e de hipertrofia do direito penal (AZEVEDO, 2017; SOUZA, 2017): no caso do Mensalão, durante todo o processo, a acusação (e posterior condenação) de lideranças históricas do Partido dos Trabalhadores por um esquema de compra de votos no Congresso foi lida como parte de um projeto 
Da Nova República à nova direita: o bolsonarismo como sintoma mórbido Ivan Henrique de Mattos e Silva

de poder, alicerçado no aparelhamento da máquina pública e na entronização nas estruturas do Estado, com vistas à subversão da democracia e à concretização do mito da síntese Partido-Estado3; no caso da Lava Jato, para além da flexibilização de garantias constitucionais fundamentais em função de um imperativo de condenação como único resultado aceitável do processo penal, fica evidente a mobilização de uma autoimagem redentora da política por parte de parcelas expressivas do Judiciário brasileiro como sua vocação institucional, cristalizada na fala do Ministro Luís Roberto Barroso, em evento organizado pelo Globo, de que caberia ao sistema judicial a tarefa de refundar o país. ${ }^{4}$

O segundo movimento evidencia o retorno de uma tradição institucional brasileira que se imaginava superada com a consolidação da Nova República e o avanço do controle civil das Forças Armadas - em especial durante os governos FHC e Lula: a construção simbólica dos militares como Poder Moderador (STEPAN, 1975). Ainda que a transição brasileira para a democracia tenha sido controlada e conduzida pelas elites militares - que puderam, assim, manter privilégios corporativos e blindar os agentes de Estado vinculados à tortura e aos assassinatos de qualquer responsabilização penal (PEREIRA, 2010) -, a relativa estabilidade institucional da política brasileira parecia sugerir que os militares, a despeito da ausência de qualquer revisão valorativa em relação à ditadura, estavam agora circunscritos à dinâmica da caserna, deixando a política aos civis.

No entanto, desde 2014, o atual Presidente da República e então deputado federal Jair Bolsonaro passou a ser presença garantida nas formaturas de cadetes da AMAN (Academia Militar das Agulhas Negras), fazendo das cerimônias oficiais um palanque para a construção de sua posterior candidatura presidencial (LEIRNER, 2020). Antes desse período mais recente, segundo Leirner (2020), também era possível identificar um movimento claro de politiza-

3 Cf. https://amp-mg.jusbrasil.com.br/noticias/100122260/ayres-britto-mensalao-foi-um-golpe-na-democracia. Acesso em: 22 fev. 2021.

4 Cf. https://www.fecomercio.com.br/noticia/estamos-tentando-refundar-o-pais-diz-luis-roberto-barroso. Acesso em: 22 fev. 2021. 
Da Nova República à nova direita: o bolsonarismo como sintoma mórbido

ção das Forças Armadas - em especial, do Exército - desde meados da década de 2000, principalmente como reação à homologação da Terra Indígena Raposa Serra do Sol, em 2007, e ao envio ao Congresso do projeto de lei que criaria a Comissão Nacional da Verdade, em 2010. O resultado dessa mudança de perspectiva de vários segmentos das Forças Armadas foi um número recorde de candidaturas de militares para as eleições de 2018, a eleição de uma chapa composta por dois militares da reserva (um capitão e um general), e um crescimento acentuado da presença de militares (da reserva e da ativa) em funções civis.

A crise da centro-direita, por sua vez, possui dois pilares: a crise da direita moderada e democrática, capitaneada pelo PSDB, e a crise do pacto pemedebista como gramática política. O primeiro pilar foi evidenciado pelo pífio resultado eleitoral do candidato tucano à Presidência da República no primeiro turno de 2018 (apenas 5\% dos votos) e pela redução em $41 \%$ do tamanho de sua bancada na Câmara dos Deputados, e representou o ocaso da chamada direita envergonhada (POWER, 2000), que não conseguiu traduzir uma crescente - embora difusa - insatisfação popular, especialmente a partir de 2015, em capital político (PINHEIRO-MACHADO, 2019).

O segundo pilar remonta à definição de Nobre (2013) do pemedebismo como a cultura política estruturante da redemocratização brasileira, materializada pelo encastelamento institucional de uma elite política que, por um lado, passou a oferecer blindagem e governabilidade ao presidencialismo brasileiro após o impeachment de Collor, e, por outro, cobrava como moeda de troca o controle da velocidade e da amplitude das mudanças sociais. O autor sustenta que - embora gestado durante a oposição à ditadura militar - o pemedebismo como fenômeno político central circunda a premissa de que seria inevitável para a manutenção da governabilidade no Brasil a existência de supermaiorias parlamentares - premissa construída ao longo dos dois governos FHC e retomada no governo Lula após a crise do chamado "mensalão", em 2005. É importante salientar que o conceito de pemedebismo, nessa chave, não se resume ao PMDB (hoje MDB), mas compreen- 
Da Nova República à nova direita: o bolsonarismo como sintoma mórbido

de uma lógica que perpassa vários partidos do chamado Centrão contemporâneo. Ainda segundo Nobre (2013), sua consolidação enquanto cultura política dominante possui três etapas:

1. Seu embrião é a união contra a ditadura militar no seio do Movimento Democrático Brasileiro, materializada no consenso do campo no Colégio Eleitoral em favor da chapa Tancredo-Sarney;

2. A união ensejada na luta contra a ditadura conflui para o chamado Centrão, durante a Assembleia Nacional Constituinte de 1987-1988, que se constitui na primeira blindagem do nascente sistema político brasileiro contra as pressões por mudanças mais estruturais;

3. A partir do impeachment do Presidente Collor, em 1992, consolidou-se a constatação de que a existência de esmagadoras maiorias parlamentares era essencial para a governabilidade, estruturando um padrão de relação entre Executivo e Legislativo - primeiro com o Presidente FHC e, depois, com o Presidente Lula - que, ao mesmo tempo em que garantia algum grau de estabilidade ao chefe do Executivo, cobrava deste o controle e a profundidade das mudanças sociais. Ambos os presidentes recorreram - em maior ou menor grau - a supermaiorias parlamentares como estratégia de sustentação da governabilidade - em vários casos, mobilizando os mesmos atores e partidos.

A centralidade do pemedebismo como cultura política na Nova República foi tamanha que, num intervalo de 31 anos (19852016), o PMDB (expressão maior dessa cultura) permaneceu por 27 anos em coalisões governistas - à exceção do governo Collor e do início do governo Lula (GUILHERME, 2017). Se, por um lado, o governo Lula manteve a lógica do pacto pemedebista como elemento estruturante da dinâmica institucional da Nova República, o mesmo não ocorreu com a sua sucessora. A conturbada relação 
Da Nova República à nova direita: o bolsonarismo como sintoma mórbido Ivan Henrique de Mattos e Silva

entre o governo da Presidenta Dilma e a sua base aliada - manifesta desde os primeiros momentos - chegou ao ápice com o golpe parlamentar que sacramenta a sua destituição em 2016, em um processo encabeçado pelo seu vice, Michel Temer, então Presidente do PMDB.

O quarto e quinto movimentos estão intimamente relacionados: segundo Pinheiro-Machado (2019), a crise internacional de 2008 agudiza a precarização e a flexibilização do trabalho pari passu a uma trajetória acentuada de pauperização das classes populares em todo o mundo, ${ }^{5}$ em um processo que encontra seu desaguadouro em uma crescente (e difusa) insatisfação social, traduzida como revolta contra o status quo: o enfraquecimento dramático da classe política estabelecida, dos partidos e das instituições basilares da democracia representativa são, assim, a vertente institucional de uma crise multifacetada que engloba a precarização do trabalho, o endividamento familiar e o encarceramento em massa (FRASER, 2018). A dramaticidade dessa crise também se traduziu em um impasse estrutural:

Após a crise de 2008, o capital entrou em um impasse: a bancarrota do modelo de acumulação neoliberal sem a perspectiva de uma nova resolução de acumulação internacional. O resultado para o mundo do trabalho também não poderia ser outro. Não se tratou de negar os métodos do período neoliberal - já que não se encontrara outro padrão de acumulação capaz de levar a uma metamorfose completa e mais abrupta -, mas sim de buscar aprofundá-los dentro das novas condições econômicas, o que só poderia levar a formas de decomposição do trabalho e da estrutura produtiva de muitos países, em nome da ação de engordar as massas de lucro de um conjunto de monopólios (TONELO, 2020, p. 141-142).

\footnotetext{
5 No caso brasileiro, todavia, esse processo (bem como os próprios efeitos da crise inaugurada em 2008) só se manifestaria de modo mais sintomático após meados da década de 2010, de modo concomitante à desestruturação do governo Dilma (POCHMANN, 2017).
} 
Da Nova República à nova direita: o bolsonarismo como sintoma mórbido

A crise de 2008 abriu, assim, espaço para um novo tipo de ativismo marcado pela horizontalidade, pela ação direta e pela atuação microscópica, definido por Pinheiro-Machado (2019) como vinculado a uma lógica prefigurativa de lutas, ou seja, pautada pela premissa de que as lutas sociais não podem reproduzir internamente as hierarquias que combatem. Essa nova modalidade de ativismo busca romper a distância entre a ação e o devir, concebendo os protestos não apenas como um meio, mas como um fim em si mesmo, como experimentação social engajada da sociedade que se busca construir (PINHEIRO-MACHADO, 2019). Comentando as características do movimento Occupy Wall Street, a autora afirma:

\begin{abstract}
A natureza radicalmente democrática dos protestos seria uma antítese da natureza desagregadora do trabalho no neoliberalismo, em que o trabalhador muitas vezes tem uma rotina repetitiva, exaustiva e solitária. Por isso, haveria necessidade de forjar uma sociabilidade reversa nos acampamentos. Assim, as ocupações urbanas precisavam virar do avesso o individualismo e a chamada racionalidade neoliberal que imperam em nosso cotidiano: eram um basta à indiferença das multidões anônimas das cidades (PINHEIRO-MACHADO, 2019, p. 21-22).
\end{abstract}

Em meio à efervescência social experimentada em todo o mundo em consequência da crise de 2008 - Occupy, nos Estados Unidos (2011), manifestações anti-austeridade, na Europa (2011), mobilizações por mais democracia, na China (2011), Primavera Árabe (2011), e as manifestações em Hong Kong contra a interferência do Partido Comunista Chinês (2014) -, o governo da Presidenta Dilma Rousseff gozava de expressiva aprovação popular, com uma economia que ainda não esboçava quaisquer sinais de retração significativa, até que, em 2013, é surpreendido pela maior onda de manifestações populares registradas até então, fazendo despencar seus índices de avaliação positiva. A partir de então, o crescente discurso antipolítico, a queda acentuada da confiança pública nas instituições formais da política brasileira (do 
Da Nova República à nova direita: o bolsonarismo como sintoma mórbido Ivan Henrique de Mattos e Silva

Parlamento aos partidos e sindicatos) e o rechaço aos instrumentos de intermediação de interesses típicos de uma democracia liberal (PINHEIRO-MACHADO, 2019), aliados à incapacidade das elites políticas estabelecidas de oferecer respostas à altura das insatisfações irrompidas nas ruas de todo o país, paulatinamente davam o tom do interregno que se avizinhava.

Como explicar a irrupção de manifestações populares de junho de 2013? Pinheiro-Machado (2019) aponta cinco elementos causais para essa explosão contestatória:

1. A ascensão econômica dos indivíduos por intermédio do processo de inclusão social pelo consumo criou sujeitos mais críticos e exigentes, agora dotados de recursos políticos e econômicos mais expressivos;

2. As políticas petistas de inclusão social - sobretudo em relação à democratização do acesso e da permanência nas universidades - tiveram como uma das consequências a consolidação de uma geração mais engajada em defesa de direitos culturais, sociais e simbólicos;

3. A inclusão social proporcionada pelas políticas de proteção social não foi acompanhada de uma melhoria equivalente nos bens e serviços sociais;

4. A ascensão de uma geração que - especialmente após o aprofundamento do pragmatismo petista na sequência do processo do Mensalão - cresceu compreendendo o Partido dos Trabalhadores como a ordem ou o establishment;

5. A reação das classes médias às mudanças na estrutura econômica e social do Brasil, interpretadas - em uma sociedade cuja herança escravocrata é estruturante em sua gênese social - como "insubordinação" das classes populares -, elemento também apontado por Souza (2017). 
Da Nova República à nova direita: o bolsonarismo como sintoma mórbido

As marchas de junho de 2013 representaram o primeiro ciclo de manifestações desde o final da década de 1970 que não teve no Partido dos Trabalhadores (ou suas bases, quando antes de sua fundação) um protagonista. Essas manifestações representaram a face mais visível e emblemática do esgotamento de um modelo político que começou a se construir durante o processo de redemocratização, e que encontrou no lulismo o seu ápice (FERNANDES, 2019; PINHEIRO-MACHADO, FREIXO, 2019). Em outras palavras, junho de 2013 representou uma manifestação aguda da crise de hegemonia do pacto social de dominação política engendrado pela Nova República, que, agora, agonizava em praça pública:

\begin{abstract}
Esse foi um dos cursos d'água que desaguaram nas massivas mobilizações de junho de 2013, que chamaram a atenção pelo alto grau de conflituosidade social. Ao lado das performances típicas dos movimentos sociais, teve lugar o confronto violento, com o aumento da repressão, prisões e mortes de manifestantes. Esse evento, de causalidade múltipla, precede uma grave crise política e econômica que pôs fim à Nova República (TATAGIBA, 2021, p. 447).
\end{abstract}

Arantes (2015) aponta, ainda, outro elemento fundamental de distinção presente nessas manifestações: em meio a um absoluto consenso construído no processo de redemocratização em torno dos próprios limites da ação - e, mesmo, da forma - política contemporânea, reduzida à disputa por recursos escassos traduzidos em políticas públicas, a juventude presente nas marchas teria operado uma espécie de "insurgência profanatória" em busca de uma "utopia real". As planilhas com os limites orçamentários apresentadas pela burocracia do poder público municipal em várias das capitais onde essas mobilizações ocorreram (em especial na cidade de São Paulo) como justificativa para a não concessão da gratuidade completa do transporte público não pareciam (sob a ótica da juventude mobilizada) um argumento legítimo ante a eloquência da contestação (CHAUI, 2003; ARANTES, 2015). Mais do 
Da Nova República à nova direita: o bolsonarismo como sintoma mórbido Ivan Henrique de Mattos e Silva

que simples intransigência juvenil (ou irresponsabilidade) - como afirmado em distintos ambientes da esfera pública -, essa postura parecia traduzir em essência o próprio esgotamento - ou, ao menos, a evidente corrosão - das formas políticas tradicionais da democracia representativa: como em um leito de Procusto, suas instituições amputavam qualquer esforço de imaginação política que extrapolasse os rígidos limites da racionalidade contábil.

Todavia, a despeito das leituras mais mecanicistas do fenômeno - dentro e fora da academia -, as mobilizações de 2013 produziram efeitos duradouros e, ao mesmo tempo, contraditórios no tecido social, ideológico e institucional do país. Se, por um lado, contribuíram para consolidar no imaginário coletivo o que Chaui (2013) define como o pensamento mágico no campo da política em que os resultados podem advir diretamente da manifestação das demandas, sem necessidade de mediação (aprofundando, assim, a descrença nas instituições estruturantes da democracia representativa) -, por outro, operaram como o desaguadouro de um conjunto de insatisfações que foram canalizadas em duas direções distintas: os "legados" de 2013 contemplam tanto um avanço brutal da extrema-direita como também uma profusão de ocupações estudantis, movimentos sociais descentralizados e coletivos feministas.

O conjunto de manifestações de junho de 2013 forneceu - em grande medida - o padrão logístico, organizacional, comunicativo e mesmo estético de uma série de novos movimentos sociais vinculados ao campo liberal-conservador, que foram atores centrais nas mobilizações pelo impeachment durante 2015 e 2016 (MBL, Revoltados Online, Vem pra Rua etc.) (MESSEMBERG, 2017; ROCHA, 2018; ROCHA, SOLANO, 2021), ao mesmo tempo em que ajudou a forjar politicamente - a partir dessa mesma lógica prefigurativa - as balizas que fundamentaram a ação do movimento estudantil secundarista nas ocupações de escolas em 2016 (que tiveram um papel central de coletivos feministas) (PINHEIRO-MACHADO, 2019). Sob os marcos de um transbordamento de uma série de descontentamentos (ANTUNES, 2013), o ano de 2013 é, ainda, o 
Da Nova República à nova direita: o bolsonarismo como sintoma mórbido Ivan Henrique de Mattos e Silva

marco simbólico da inauguração do que Pinheiro-Machado (2019) define como revoltas ambíguas ou revoltas do precariado. A respeito de sua ambiguidade, Singer (2013) afirma:

Socialmente heterogêneos, os acontecimentos de junho foram também tão multifacetados no plano das propostas que não espanta haja todo tipo de imputação ao seu sentido ideológico: desde o ecossocialismo até impulsos fascistas, passando por diversas gradações de reformismo e liberalismo. Acabaram por ser uma espécie de "Jornadas de Juno", cada um vendo nas nuvens levantadas nas ruas a forma de uma deusa diferente (SINGER, 2013, p. 32).

Dada a especificidade da estruturação das classes trabalhadoras no padrão neoliberal de acumulação capitalista - marcadas pela precarização, atomização e flexibilização -, as manifestações encabeçadas pelo precariado (BRAGA, 2012) não apenas rejeitam as organizações coletivas tradicionais como instâncias legítimas de representação (como os partidos e sindicatos), mas, sobretudo, apresentam uma natureza ideológica essencialmente contraditória e em disputa - como, por exemplo, os "rolezinhos" e a greve dos caminhoneiros (PINHEIRO-MACHADO, 2019). Enquanto centro-esquerda e centro-direita "assistiam bestializadas" à insurgência complexa e contraditória do precariado, a nova direita conseguiu capturar o signo dessa indignação difusa e convertê-la em capital político.

O sexto movimento diz respeito à crescente participação das igrejas pentecostais e neopentecostais na vida pública brasileira, e, em especial, ao seu papel enquanto aparelhos privados de hegemonia 6 . Segundo Freston (1994) e Burity (2018), os pentecostais surgem como atores na cena pública brasileira por volta de meados da década de 1980 - representando, naquele momento, metade de toda a população protestante no país, e, hoje, dois terços do total -, com uma atuação política pautada, desde o início, por um

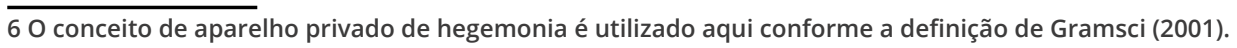


Da Nova República à nova direita: o bolsonarismo como sintoma mórbido Ivan Henrique de Mattos e Silva

perfil preponderantemente conservador (tanto no campo político como no campo moral), ancorado retoricamente nas teses da perseguição religiosa e da ameaça comunista (BURITY, 2018). Embora tenham cumprido um papel político significativo (ainda que sem uma atuação coordenada), sua atuação até 2014 esteve majoritariamente limitada ora à condição de veto player, para utilizar o conceito de Tsebelis (2002), bloqueando o avanço de certas pautas progressistas - em especial aquelas relacionadas aos direitos civis e/ou reprodutivos -, ora à posição de plataforma de barganha de cargos e ministérios - como durante o governo Sarney (FRESTON, 1994) e os governos FHC, Lula e Dilma. Após 2014, entretanto, houve um processo de autonomização política bastante significativo desse campo:

Na conjuntura pós-eleições presidenciais de 2014, a desenvoltura e o protagonismo com que o bloco pentecostal hegemônico ("os evangélicos"/a "bancada evangélica") se moveu entre o Legislativo e o Executivo e mobilizou a "sociedade civil" e a "indústria cultural" evangélicas do país em seu favor projetaram esse ator de forma notável no cenário político que foi e conformando até o desfecho do processo de impeachment da presidenta Dilma Rousseff e a formação do governo do ex-vice-presidente Michel Temer (BURITY, 2018, p. 17, grifo do autor).

Almeida (2018) aponta três eixos da atuação "evangélica" nessa onda conservadora que são fundamentais para a reflexão empreendida aqui:

1. Defesa do livre-mercado, da meritocracia e do empreendedorismo - fortemente ancorada na Teologia da Prosperidade (que possui uma profunda afinidade de sentido com a informalidade, a individualização e a precariedade das relações de trabalho contemporâneas) e na construção simbólica de uma "disposição empreendedora" 
Da Nova República à nova direita: o bolsonarismo como sintoma mórbido

que compreende os riscos do empreendimento econômico como sinal de fé;

2. Disputa pela moralidade pública - que significaria uma guinada importante nas estratégias do campo pentecostal até então, saindo de uma posição que buscava resguardar a inviolabilidade normativa e moral dos seus espaços específicos, para uma perspectiva de contenção dos avanços do secularismo no espaço público, buscando inscrever sua moralidade privada na ordem legal do país;

3. Punitivismo estatal - marcado pela adesão às pautas da redução da maioridade penal, do armamento da população civil e da militarização do ensino e da sociedade no Brasil, em consonância com uma compreensão da realidade social brasileira como o estado de natureza hobbesiano.

Ademais, a teologia pentecostal forneceu novos significados para a vida sofrida pari passu a uma teleologia da redenção: ao aderir integralmente à "revolução contrarrevolucionária" do discurso bolsonarista, as classes populares poderiam vislumbrar viver numa comunidade redimida - livre dos bandidos, corruptos e desviantes -, materializada no formato da "família cristã" (FELTRAN, 2020):

O apelo pentecostal entre as massas não se dá tanto pela proposta de aderir a confissões ou doutrinas específicas, como no fundamentalismo americano histórico, mas pela promessa - cumprida - de fortalecimento dos vínculos comunitários, de afirmação de sua dignidade, a despeito das estreitas margens de reconhecimento igualitário (até mesmo legal) por parte das instituições estatais e da sociedade majoritária, e de construção de uma imagem de assertividade e pujança na relação com as elites políticas e culturais do país (BURITY, 2018, p. 45, grifo do autor). 
Da Nova República à nova direita: o bolsonarismo como sintoma mórbido

A ascensão de novos grupos políticos abertamente identificados com uma direita reinventada no século XXI (sétimo movimento em análise) é um fenômeno internacional (CARAPANÃ, 2018; MARQUEZ; BERGAMINI; LIMA, 2019; PINHEIRO-MACHADO, 2019; ROCHA, 2018; SOLANO, 2018), resultado de um profundo reordenamento político e ideológico como consequência direta da crise estrutural pela qual passa o capitalismo de matriz neoliberal desde 2008 (FRASER, 2018; PINHEIRO-MACHADO, 2019). No caso brasileiro, a crise sistêmica que se estrutura no país em meados da década de 2010 foi a grande janela de oportunidades para que a nova direita - na esteira de um longo processo de disputa ideológica e cultural em distintas esferas da sociedade civil - pudesse se converter em ator político central e conquistasse, em 2018, a Presidência da República com a coalização de forças liderada por Jair Bolsonaro.

Cinco características fundamentam a distinção desses novos grupos políticos em relação aos seus congêneres anteriores: a centralidade da disputa cultural como condição ex ante para a conquista do poder político (ALEXANDRE, 2017; PUGLIA, 2018; ROCHA, 2018; SEDGWICK, 2019; TEITELBAUM, 2019, 2020); o anti-intelectualismo, enquanto rejeição das instâncias tradicionais de produção e legitimação de regimes de verdade - em especial, as universidades (ALONSO, 2019; PINHEIRO-MACHADO, 2019; TEITELBAUM, 2020); O antielitismo, enquanto valorização ética, estética e epistemológica do homem médio e do senso comum - e, por extensão, a defesa de um atributo de liderança como representação arquetípica do indivíduo mediano (ALONSO, 2019); a instrumentalização do discurso "politicamente incorreto" como uma retórica de resistência anti-sistema (DI CARLO, KAMRADT, 2018; ROCHA, 2018); e a síntese entre o conservadorismo moral e a defesa do livre-mercado (CHALOUB, PERLATTO, 2015; ROCHA, 2018; NETTO; CAVALCANTE; CHAGURI, 2019).

Embora a manifestação mais aparente da nova direita brasileira seja bastante recente - sobretudo após as manifestações de junho de 2013, em menor medida, e, principalmente, após os protestos 
Da Nova República à nova direita: o bolsonarismo como sintoma mórbido Ivan Henrique de Mattos e Silva

pelo impeachment da Presidenta Dilma Rousseff em 2015 e 2016 -, a sua gestação coincide com o auge da popularidade do governo Lula (entre 2006 e 2010), e se dá, segundo Rocha (2018), a partir da organização de um contra-público em grupos de discussão, redes sociais e fóruns da internet ancorados em pautas radicalizadas e em uma linguagem debochada. Como as pautas e bandeiras mais radicalizadas à direita não encontravam guarida na esfera pública gestada pela Nova República, esses grupos encontraram, na internet - apoiados, inclusive, no recurso do anonimato -, um ambiente para o reconhecimento de seus semelhantes e a possibilidade de construção de uma plataforma discursiva comum, apoiada, em grande medida, na visão de mundo oferecida pela obra de Olavo de Carvalho (ROCHA, 2018).

Devido à sua capacidade de fornecer o campo semântico que possibilitou a coesão ideológica e estratégica entre distintos grupos políticos e sociais, por um lado, e de traduzir um conjunto de teses e valores das direitas internacionais reinventadas - em especial o paleoconservadorismo nos Estados Unidos na segunda metade do século XX - para o contexto brasileiro, fornecendo, assim, corpo explicativo para o ressentimento e a indignação difusa de vastas parcelas da população brasileira, por outro, Olavo de Carvalho é o principal intelectual orgânico dessa nova direita, e o olavismo enquanto linguagem política derivada da sua leitura da realidade -, um elemento estruturante da metapolítica ${ }^{7}$ bolsonarista (SILVA, 2021).

É a partir da condição de contra-público que a nova direita conquista paulatinamente novas posições no tecido social brasileiro, constituindo, inclusive, o ponto de partida dos grupos pró-impeachment, o núcleo duro do Partido Novo, os artífices da reorientação do PSC após 2014 e alguns dos principais articuladores do crescimento da competitividade eleitoral do deputado Jair Bolsonaro desde 2016 até a campanha presidencial de 2018 (ROCHA, 2018):

7 Estratégia que identifica na arena cultural um lócus privilegiado de disputa política. 
Da Nova República à nova direita: o bolsonarismo como sintoma mórbido Ivan Henrique de Mattos e Silva

Entre 2007 e 2013 os ultraliberais, em conjunto com outros militantes que além do livre-mercado defendiam pautas conservadoras, passaram a circular em novas e antigas organizações civis, grupos e movimentos de defesa do livre-mercado e a formar grupos de estudo e chapas para disputa de centros e diretórios acadêmicos em universidades públicas (ROCHA, 2018, p. 17).

É importante salientar, ainda, que há uma profunda afinidade de sentido entre o olavismo e o Weltanschauung 8 propagado pelo pentecostalismo enquanto "partido religioso", especialmente em três chaves: a tese de que a civilização não pode prescindir de uma sólida base espiritual (TEITELBAUM, 2020); a compreensão da realidade como naturalmente trágica, conflitiva, desigual e permeada de conspirações (ROCHA, 2021); e a compreensão da mobilização política e ideológica como promessa redentora para uma vida (individual e coletiva) degenerada, rumo à elevação da família tradicional como categoria ordenadora do mundo social (NETTO; CAVALCANTE; CHAGURI, 2019; FELTRAN, 2020).

$\mathrm{O}$ argumento sustentado aqui é que, longe de representar (pelo menos por enquanto) uma superação (à direita) da crise da Nova República, a eleição de Jair Bolsonaro - corolário da ascensão ideológica da nova direita brasileira - é uma manifestação sintomática da própria incapacidade das classes dominantes de reordenar um pacto de dominação social e política no país. Em outras palavras, é um sintoma de sua incapacidade de se reconverterem em classes dirigentes - característica mais elementar do interregno brasileiro. A dificuldade do governo Bolsonaro de colocar em prática as reformas estruturais prometidas ao "mercado" (essa entidade aparentemente metafísica) - condição indispensável para a manutenção do apoio do capital financeiro ao arranjo bolsonarista -, bem como a própria condição dúbia do bolsonarismo, que se equilibra com dificuldade entre sua configuração ora como governo e ora como movimento (AVRITZER, 2021; COUTO, 2021), traduzem bem essa incapacidade e, por extensão, a natureza essencial desse interregno.

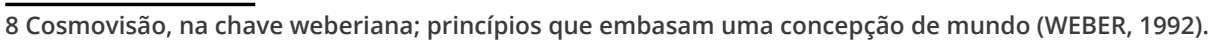




\section{Considerações finais - o interregno brasileiro e seus sin- tomas mórbidos}

A discussão de Gramsci sobre o conceito de interregno está situada na análise que o intelectual sardo faz da situação da Itália no início do século XX: a crise italiana após a Primeira Guerra Mundial possuía, então, uma natureza orgânica, de modo que não se tratava apenas de uma questão de desequilíbrios em sua estrutura econômica, mas de uma crise de hegemonia das suas classes dirigentes - que deixam de sê-lo para se converterem em apenas classes dominantes, ou seja, detentoras puramente de força coercitiva (GRAMSCl, 2017; FRESU, 2020). Ao mesmo tempo, os limites do socialismo italiano - preso em conflitos internos paralisantes -, inviabilizavam a construção de qualquer tipo de síntese que pudesse superar a paralisia histórica. Nesse sentido, para fazer referência à célebre afirmação gramsciana, a crise consistia "justamente no fato de que o velho morre e o novo ainda não pode nascer: nesse interregno, verificam-se os fenômenos patológicos ${ }^{9}$ mais variados" (GRAMSCI, 2017, p. 184). Interregno para Gramsci é, portanto, um período de paralisia histórica; de uma crise de hegemonia que representa a agonia do velho mundo junto à impossibilidade do novo enquanto realização política, histórica e social:

Quando se verifica tal fratura, estamos diante de uma condição de "crise de hegemonia": os grupos sociais se distanciam de seus partidos tradicionais, não reconhecendo mais em seus próprios dirigentes a expressão política de seus interesses de classe. Em situações desse tipo, multiplicam-se as possíveis soluções de força, os riscos de subversivismo reacionário, de operações obscuras sob a liderança de chefes carismáticos. A determinação dessa fratura entre representantes e representados leva, por reflexo, ao reforço de todos aqueles organismos relativamente independentes das oscilações da opinião pública, como a burocracia militar e civil, a alta finança, a Igreja (FRESU, 2020, p. 284-285).

9A expressão "fenômenos patológicos" também pode ser traduzida como "sintomas mórbidos" - do italiano fenomeni morbosi. 
Da Nova República à nova direita: o bolsonarismo como sintoma mórbido

No caso brasileiro, o interregno é derivado da corrosão dos fundamentos ideológicos e estruturais que tornaram possível o arranjo da Nova República, em um processo enormemente potencializado pela agudização dos efeitos da crise da sociabilidade capitalista em sua fase neoliberal pós-2008: do ponto de vista ideológico, a instrumentalização do politicamente incorreto como retórica política (DI CARLO, KAMRADT, 2018) - apoiado na leitura de mundo oferecida pela narrativa de Olavo de Carvalho pavimentou o caminho para a supressão do consenso até então existente em torno de um campo semântico de matriz inclusiva e tolerante. A estética revolucionária assumida por seus porta-vozes (políticos, editoriais e humorísticos) tornou possível à nova direita a captura do signo da revolta popular contra "o sistema" (BIANCHI, MELO, 2018), apresentando a si mesma como parteira de um novo mundo, e, a Bolsonaro, como o "messias" - o "mito" redentor de um processo ao mesmo tempo transcendente e imanente.

A incapacidade da esquerda hegemônica brasileira - capitaneada pelo Partido dos Trabalhadores - de lidar tanto com o encurtamento da margem de ação política após o arrefecimento dos preços das commodities (e, portanto, a agudização da luta de classes) e o aprofundamento da crise econômica, quanto com a explosão de novas demandas vinculadas a uma classe trabalhadora de novo tipo (TONELO, 2020), também impediu qualquer síntese que pudesse superar aquela paralisia histórica, possibilitando que os novos revolucionários da contrarrevolução brasileira capturassem o signo e a semântica da revolta e da insatisfação.

A reação conservadora no Brasil passa a ser lida, portanto, a partir do signo de uma reação ao próprio modelo de subjetivação nucleada na tolerância (BURITY, 2018). A aversão à diferença compõe um elemento central do bolsonarismo (FELTRAN, 2020). Não à toa as chamadas pautas identitárias foram elevadas ao centro da disputa discursiva da nova direita, que identifica nelas uma arma para a destruição dos próprios valores e fundamentos da civilização ocidental (ASHBEE, 2019): o descompasso existente entre a agenda da redistribuição e a agenda do reconhecimen- 
Da Nova República à nova direita: o bolsonarismo como sintoma mórbido Ivan Henrique de Mattos e Silva

to - típico daquilo que Fraser (2018) define como neoliberalismo progressista -, em especial em meio ao aprofundamento da crise estrutural do capitalismo neoliberal, faz com que os avanços verificados na agenda do reconhecimento sejam recebidos por vastas parcelas das classes populares como perdas relativas (sobretudo por parte do precariado masculino e/ou branco) e ressignificados politicamente como ressentimento ou "raiva cultural" (BURITY, 2018; BROWN, 2019; PINHEIRO-MACHADO, 2019). A raiva cultural é um importante componente da ascensão política e ideológica do conservadorismo contemporâneo (GREEN, 2007):

O que eu quero dizer com "raiva cultural"? É o sentimento, por parte de milhões de pessoas, de que elas estão de alguma maneira excluídas da cultura em ambos os sentidos correntes da palavra. Elas se sentem excluídas da representação nas instituições que produzem comunicação de massa, bem como do conteúdo dessa comunicação; a ordem social da qual elas se sentem excluídas é o que os antropólogos chamam de ordem simbólica (GREEN, 2007, p. 32, grifo do autor). ${ }^{10}$

\section{6}

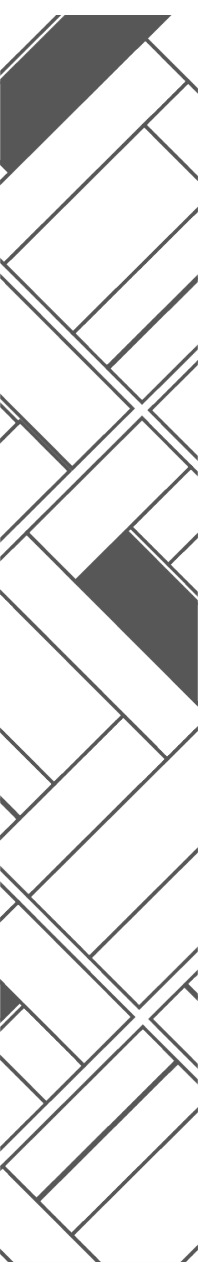

A crise estrutural do capitalismo neoliberal também opera a corrosão das próprias bases materiais que forneceram o esteio sobre o qual se construiu a repactuação política e social no país: sendo o neoliberalismo permeado por um processo de constante destruição de coletividades (PINHEIRO-MACHADO, 2019), a terceirização e a precarização do trabalho decorrentes da reestruturação produtiva demandada pelas novas formas de acumulação no capitalismo pós-fordista engendram uma nova classe trabalhadora bastante heterogênea e fragmentada: o precariado. A invisibilização das relações de trabalho e assalariamento nesse contexto de precarização escamoteia as lógicas de exploração do trabalho que, agora, se apresentam sob a falsa aparência da livre prestação de serviços, simbolicamente significada como emancipação (ANTUNES, 2020). Considerada a sua especificidade histórica e es-

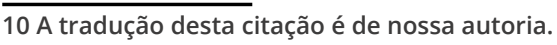


Da Nova República à nova direita: o bolsonarismo como sintoma mórbido Ivan Henrique de Mattos e Silva

trutural - vale dizer, a precarização, a flexibilização e o isolamento -, duas lógicas se mostram fortemente capazes de enraizamento social: o empreendedorismo e a teologia da prosperidade (CHAUI, 2013; ALMEIDA, 2019).

Para além das diretrizes preconizadas pelo chamado Consenso de Washington, o neoliberalismo compreende tanto uma reestruturação ampla do campo teórico e normativo liberal - que rejeita igualmente a ideia dogmática dos automatismos de mercado do laissez-faire do século XIX e o resgate do distributivismo no início do século XX por parte de autores como Keynes, Hobson, Hobhouse e Dewey -, apresentando uma defesa do papel ativo do Estado na reposição constante dos mecanismos de competição de mercado, como a criação de uma racionalidade específica, pautada por um modelo de subjetivação nucleado na forma empresa (DARDOT; LAVAL, 2016). Ou seja: os indivíduos passam a se construir subjetivamente como se fossem empresas, num processo de competição constante com seus semelhantes, atuando no sentido de maximizar as suas habilidades (compreendidas enquanto bens de capital). Essa é a ética do empreendedorismo (DARDOT; LAVAL, 2016).

A teologia da prosperidade (vinculada às igrejas neopentecostais - que, em sua maioria, dedicaram apoio sistemático e contundente à candidatura de Jair Bolsonaro em 2018), por sua vez, distingue-se tanto da ética protestante - uma ética do trabalho, da disciplina e da conduta metódica, por intermédio de uma ascese intramundana, estimulada pela doutrina religiosa (WEBER, 2004) - como da ética da providência - do pentecostalismo tradicional, sustentada pela noção de que deus provê àqueles que permanecem fiéis nas dificuldades (ALMEIDA, 2019). Assim:

A teologia da prosperidade prega uma ética econômica voltada para o mundo, em que possuir e ascender são sinais de que Deus, e não o diabo, age em sua vida. Essa ascensão não se ancora especificamente na disciplina e na dedicação ao trabalho, mas em uma disposição empreendedora de quem almeja se tornar o patrão nas relações de trabalho (ALMEIDA, 2019, p. 41). 
Da Nova República à nova direita: o bolsonarismo como sintoma mórbido

Ainda segundo Almeida (2019):

\begin{abstract}
Cada vez mais essa concepção se dissemina pelo meio evangélico e além dele. Ela estabeleceu uma afinidade de sentido com a informalidade e com a precariedade do trabalho, como ocorreu no Brasil nos anos de recessão econômica, nas décadas de 1980 e 1990, e também nos momentos de expansão do consumo, como nos anos 2000 (ALMEIDA, 2019, p. 46).
\end{abstract}

Sendo uma "religião intramundana", ela operaria como um sistema simbólico que não apenas dá sentido às ações, mas motiva e desperta o fiel para uma práxis específica que não compreende a desconstrução das desigualdades (como no igualitarismo presente no cristianismo primitivo ou na teologia da libertação), assumidas como inerentes à vida coletiva, mas permite a ascensão individual em meio às relações de desigualdade (ALMEIDA, 2019). As desigualdades, portanto, passam a ser ao mesmo tempo naturalizadas e valorizadas. O empreendedorismo e a teologia da prosperidade são duas faces da mesma moeda: o verniz ideológico da crise da sociabilidade neoliberal, ou seja, a expressão superestrutural do próprio processo de acumulação capitalista periférica marcado pela expansão do precariado.

Se o fascismo histórico foi uma resposta à crise de hegemonia e à incapacidade das classes dirigentes na Itália de manter a ordem política por meio dos instrumentos tradicionais da democracia liberal, convertendo-se numa síntese de partido-movimento (BIANCHI; MELO, 2018; FRESU, 2020), a ascensão da nova direita no Brasil é uma resposta brasileira à crise de hegemonia e à incapacidade das suas classes dirigentes de manter o pacto de dominação política engendrado pela Nova República. Tal como o fascismo histórico, o bolsonarismo é, também, um fenômeno de massas e de base popular, mas, diferente daquele, não possui seu núcleo duro de sustentação na pequena burguesia, e sim no precariado - a classe trabalhadora marcada pela flexibilização e pela precarização do trabalho típicas do padrão de acumulação neoliberal 
Da Nova República à nova direita: o bolsonarismo como sintoma mórbido Ivan Henrique de Mattos e Silva

(BRAGA, 2019). O ressentimento como reação a um senso de perda relativa - seja em relação aos ganhos simbólicos das "minorias", ou em relação à reversão de sua trajetória de inclusão pelo consumo verificada durante o auge do lulismo - é um componente cultural central da adesão do precariado à lógica bolsonarista (NETTO; CAVALCANTE; CHAGURI, 2019; PINHEIRO-MACHADO, 2019).

Apesar de ser um equívoco equiparar bolsonarismo e fascismo (BIANCHI; MELO, 2018), há importantes aproximações, sobretudo em relação ao seu potencial de capturar o signo da revolta sistêmica em uma direção ultraconservadora, convertendo seus porta-vozes naquilo que Hobsbawm (2008) definia (em relação aos fascistas) como os revolucionários da contrarrevolução. Embora a nova direita não tenha construído um robusto partido de massas que sintetizasse o seu núcleo orgânico, o bolsonarismo ensejou a construção de uma síntese de governo-movimento (COUTO, 2021). O bolsonarismo é, assim, a manifestação mais cristalina dos sintomas mórbidos do interregno brasileiro.

\section{9}

\section{Referências}

ALEXANDRE, Thiago de Andrade Romeu. O Instituto Millenium e os intelectuais da "nova direita" no Brasil. Juiz de Fora, 2017. 117 f. Dissertação (Mestrado em Ciências Sociais) - Instituto de Ciências Humanas, Universidade Federal de Juiz de Fora, Juiz de Fora, 2017.

ALMEIDA, Ronaldo de. Deus acima de todos. In: Democracia em Risco? 22 ensaios sobre o Brasil hoje. São Paulo: Companhia das Letras, 2019. p. 35-51.

ALMEIDA, Ronaldo de. Deuses do Parlamento: os impedimentos de Dilma. In: ALMEIDA, Ronaldo de; TONIOL, Rodrigo (orgs.). Conservadorismos, Fascismos e Fundamentalismos - Análises conjunturais. Campinas: Editora da Unicamp, 2018. p. 163-194. 
Da Nova República à nova direita: o bolsonarismo como sintoma mórbido

ALONSO, Angela. A comunidade moral bolsonarista. In:

Democracia em Risco? 22 ensaios sobre o Brasil hoje. São Paulo: Companhia das Letras, 2019. p. 52-70.

ANTUNES, Ricardo. As rebeliões de junho de 2013. Observatório Social de América Latina, Buenos Aires, v. 14, n. 34, p. 37-48, 2013.

ANTUNES, Ricardo. Trabalho intermitente e uberização do trabalho no limiar da Indústria 4.0. In: ANTUNES, Ricardo (org.). Uberização, trabalho digital e Indústria 4.0. São Paulo: Boitempo Editorial, 2020. p. 11-22.

ARANTES, Paulo. 0 novo tempo do mundo: e outros estudos sobre a era da emergência. São Paulo: Boitempo Editorial, 2015.

ASHBEE, Edward. Patrick J. Buchanan and the Death of the West. In: SEDGWICK, Mark (org.). Key Thinkers of the Radical Right - Behind the New Threat to Liberal Democracy. Nova lorque: Oxford University Press, 2019. p. 121-136.

AVRITZER, Leonardo. Política e antipolítica nos dois anos de governo Bolsonaro. In: AVRITZER, Leonardo; KERCHE, Fábio; MARONA, Marjorie (org.). Governo Bolsonaro: retrocesso democrático e degradação política. Belo Horizonte: Autêntica, 2021. p. 13-20.

AVRITZER, Leonardo; MARONA, Marjorie Corrêa. Judicialização da política no Brasil: ver além do constitucionalismo liberal para ver melhor. Revista Brasileira de Ciência Política, Brasília, n. 15, p. 69-94, 2014.

AZEVEDO, Fernando Antônio. A Grande Imprensa e o PT (19892014). São Carlos: EdUFSCar, 2017.

BARRUCHO, Luis. Brasil de Bolsonaro tem maior proporção de militares como ministros do que Venezuela; especialistas veem riscos. BBC News Brasil, Londres, 26 fev. 2020. Disponível em: https://www.bbc.com/portuguese/brasil-51646346. Acesso em: 19 mai. 2021. 
Da Nova República à nova direita: o bolsonarismo como sintoma mórbido

BIANCHI, Álvaro; MELO, Demian. Donald Trump é fascista? In: ALMEIDA, Ronaldo de; TONIOL, Rodrigo (orgs.).

Conservadorismos, Fascismos e Fundamentalismos - Análises conjunturais. Campinas: Editora da Unicamp, 2018. p. 67-86.

BRAGA, Ruy. A política do precariado - do populismo à hegemonia lulista. São Paulo: Boitempo Editorial, 2012.

BRAGA, Ruy. From the Union Hall to the Church. Jacobin Magazine, Nova lorque, 4 jul. 2019. Disponível em: https://www. jacobinmag.com/2019/04/bolsonaro-election-unions-labor-evangelical-churches. Acesso em: 19 maio 2021.

BROWN, Wendy. In the Ruins of Neoliberalism - the Rise of Antidemocratic Politics in the West. Nova lorque: Columbia University Press, 2019.

BURITY, Joanildo. A onda conservadora na política brasileira traz o fundamentalismo ao poder? In: ALMEIDA, Ronaldo de; TONIOL, Rodrigo (orgs.). Conservadorismos, Fascismos e Fundamentalismos - Análises conjunturais. Campinas: Editora da Unicamp, 2018. p. 15-66.

CARAPANÃ. A nova direita e a normalização do nazismo e do fascismo. In: SOLANO, Esther (org.). 0 ódio como política: a reinvenção das direitas no Brasil. São Paulo: Boitempo Editorial, 2018. p. 42-50.

CHALOUB, Jorge; PERLATTO, Fernando. Intelectuais da "nova direita" brasileira: ideias, retórica e prática política. In: ENCONTRO ANUAL DA ANPOCS, 39., 2015, Caxambu. Anais [...]. Caxambu: ANPOCS, 2015. p. 1-29.

CHAUI, Marilena. As manifestações de junho de 2013 na cidade de São Paulo. Revista Teoria e Debate, jun. 2013. Disponível em: https://teoriaedebate.org.br/2013/06/27/\%EF\%BB\%BFas-manifestacoes-de-junho-de-2013-na-cidade-de-sao-paulo/. Acesso em: 22 fev. 2021. 
COUTO, Cláudio Gonçalves. Do governo-movimento ao pacto militar-fisiológico. In: AVRITZER, Leonardo; KERCHE, Fábio; MARONA, Marjorie (org.). Governo Bolsonaro: retrocesso democrático e degradação política. Belo Horizonte: Autêntica, 2021. p. 35-50.

DARDOT, Pierre; LAVAL, Christian. A Nova Razão do Mundo: ensaio sobre a sociedade neoliberal. Tradução de Mariana Echalar. São Paulo: Boitempo Editorial, 2016.

DI CARLO, Josnei; KAMRADT, João. Bolsonaro e a Cultura do Politicamente Incorreto na Política Brasileira. Teoria e Cultura, Juiz de Fora, v. 13, n. 2, p. 55-72, 2018.

EAGLETON, Terry. Ideologia: uma introdução. Tradução de Silvana Vieira e Luís Carlos Borges. $2^{\text {a }}$ edição. São Paulo: Boitempo Editorial, 2019.

FELTRAN, Gabriel. Formas elementares da vida política: sobre o movimento totalitário no Brasil (2013-atual). Blog Novos Estudos CEBRAP, 2020. Disponível em: http://novosestudos.com.br/formas-elementares-da-vida-politica-sobre-o-movimento-totalitario-no-brasil-2013/. Acesso em: 20 maio 2021.

FERNANDES, Sabrina. Sintomas Mórbidos: a encruzilhada da esquerda brasileira. São Paulo: Autonomia Literária, 2019.

FRASER, Nancy. Do neoliberalismo progressista a Trump - e além. Tradução de Paulo S. C. Neves. Política e Sociedade, Florianópolis, v. 17, n. 40, p. 43-64, 2018.

FRESTON, Paul. Protestantes e política no Brasil: da Constituinte ao impeachment. Campinas, 1994. 308 f. Tese (Doutorado em Ciências Sociais) - Instituto de Filosofia e Ciências Humanas, Universidade Estadual de Campinas, Campinas, 1994.

FRESU, Gianni. Antonio Gramsci, o homem filósofo: uma biografia intelectual. Tradução de Rita Matos Coitinho. São Paulo: Boitempo Editorial, 2020.

GUILHERME, Cássio Augusto. Notas sobre o PMDB na Nova República: a atuação dos peemedebistas entre os governos 
Da Nova República à nova direita: o bolsonarismo como sintoma mórbido Ivan Henrique de Mattos e Silva

Sarney e Dilma (1985-2016). Revista Espaço Acadêmico, Maringá, n. 197, p. 88-101, 2017.

GRAMSCl, Antonio. Cadernos do Cárcere, vol. 2. Tradução de Carlos Nelson Coutinho. $2^{a}$ edição. Rio de Janeiro: Civilização Brasileira, 2001.

GRAMSCl, Antonio. Cadernos do Cárcere, vol. 3. Tradução de Carlos Nelson Coutinho. $8^{a}$ edição. Rio de Janeiro: Civilização Brasileira, 2017.

GRAMSCl, Antonio. Concepção Dialética da História. Tradução de Carlos Nelson Coutinho. Rio de janeiro: Civilização Brasileira, 1991.

GRAMSCl, Antonio. Os intelectuais e a organização da cultura. Tradução de Carlos Nelson Coutinho. São Paulo: Círculo do Livro, 1980.

GREEN, Philip. Cultural Rage and the Right-Wing Intellectuals. In: THOMPSON, Michael J. (org.). Confronting the New Conservatism - The Rise of the Right in America. Nova lorque/ Londres: NYU Press, 2007.

HIRSCHL, Ran. O novo constitucionalismo e a judicialização da política pura no mundo. Revista de Direito Administrativo, Rio de Janeiro, n. 251, p. 139-178, 2009.

HOBSBAWM, Eric. Era dos Extremos: o breve século XX - 19141989. Tradução de Marcos Santarrita. $2^{a}$ Edição. São Paulo: Companhia das Letras, 2008.

LEIRNER, Piero. C. O Brasil no espectro de uma guerra híbrida: militares, operações psicológicas e política em uma perspectiva etnográfica. São Paulo: Alameda, 2020.

MARQUEZ, Allan Cancian; BERGAMINI, Ana Paula Miranda Costa; LIMA, Fábio Luiz Malini de. Os Intelectuais e as Instituições de Direita no Brasil: o Deboche e a Cultura do Lacre como parte da estratégia desses atores políticos. In: CONGRESSO DE CIÊNCIAS 
Da Nova República à nova direita: o bolsonarismo como sintoma mórbido

DA COMUNICAÇÃO NA REGIÃO SUDESTE, 24., 2019, Vitória. Anais [...]. Vitória: UFES, 2019. p. 1- 15.

MARX, Karl. O Dezoito Brumário de Louis Bonaparte. Tradução de Sílvio Donizete Chagas. 5ª Edição. São Paulo: Centauro, 2006.

MASCARO, Alysson Leandro. Estado e forma política. São Paulo: Boitempo Editorial, 2015.

MESSENBERG, Débora. A direita que saiu do armário: a cosmovisão dos formadores de opinião dos manifestantes de direita brasileiros. Sociedade e Estado, Brasília, v. 32, n. 3, p. 621-647, 2017. NETTO, Michel Nicolau; CAVALCANTE, Sávio Machado; CHAGURI, Mariana Miggiolaro. O homem médio e o conservadorismo liberal no Brasil contemporâneo: o lugar da família. In: ENCONTRO ANUAL DA ANPOCS, 43., 2019, Caxambu. Anais [...]. Caxambu: ANPOCS, 2019. p. 1-18.

NOBRE, Marcos. Imobilismo em Movimento. São Paulo: Companhia das Letras, 2013.

OHANA, Victor. Dossiê faz radiografia da militarização do governo e das intervenções nas universidades. Carta Capital, 31 mar. 2021. Disponível em: https://www.cartacapital.com.br/politica/ dossie-faz-radiografia-da-militarizacao-do-governo-e-das-intervencoes-nas-universidades/. Acesso em: 19 mai. 2021.

PEREIRA, Anthony. Ditadura e Repressão - O Autoritarismo e o Estado de Direito no Brasil, Chile e na Argentina. São Paulo: Paz e Terra, 2010.

PINHEIRO-MACHADO, Rosana. Amanhã vai ser maior: O que aconteceu com o Brasil e possíveis rotas de fuga para a crise atual. São Paulo: Editora Planeta, 2019.

PINHEIRO-MACHADO, Rosana; FREIXO, Adriano de. Introdução Dias de um futuro (quase) esquecido: um país em transe, a democracia em colapso. In: PINHEIRO-MACHADO, Rosana; FREIXO, Adriano de (orgs.). Brasil em Transe: Bolsonarismo, Nova Direita 
Da Nova República à nova direita: o bolsonarismo como sintoma mórbido

e Desdemocratização. Rio de Janeiro: Oficina Raquel, 2019. p. 9-24.

POCHMANN, Marcio. Estado e capitalismo no Brasil: a inflexão atual no padrão das políticas públicas do ciclo político da Nova República. Revista Educação \& Sociedade, Campinas, v. 38, n. 139, p. 309-330, 2017.

POWER, Timothy. The Political Right in Post-Authoritarian

Brazil: Elites, Institutions and Democratization. University Park: Penn State University Press, 2000.

PUGLIA, Leonardo Seabra. Gramsci e os Intelectuais da Direita no Brasil Contemporâneo. Teoria e Cultura, Juiz de Fora, v. 13, n. 2, p. 40-54, 2018.

ROCHA, Camila. “Menos Marx, mais Mises": uma gênese da nova direita brasileira (2006-2018). São Paulo, 2018. 233 f. Tese (Doutorado em Ciência Política) - Faculdade de Filosofia, Letras e Ciências Humanas, Universidade de São Paulo, São Paulo, 2018.

\section{5}

ROCHA, João Cezar de Castro. Guerra cultural e retórica do ódio: crônicas de um Brasil pós-político. Goiânia: Editora e Livraria Caminhos, 2021.

ROCHA, Camila; SOLANO, Esther. A ascensão de Bolsonaro e as classes populares. In: AVRITZER, Leonardo; KERCHE, Fábio; MARONA, Marjorie (org.). Governo Bolsonaro: retrocesso democrático e degradação política. Belo Horizonte: Autêntica, 2021. p. 21-34.

SALLUM JR., Brasílio. Transição Política e Crise de Estado. Lua Nova, São Paulo, n. 32, p. 133-167, 1994.

SALLUM JR., Brasílio. Labirintos: dos generais à Nova República. São Paulo: Hucitec, 1996.

SALLUM JR., Brasílio. O Brasil sob Cardoso: neoliberalismo e desenvolvimentismo. Tempo Social, São Paulo, v. 11, n. 2, p. 2347, 1999. 
Da Nova República à nova direita: o bolsonarismo como sintoma mórbido

SALLUM JR., Brasílio. Metamorfoses do Estado Brasileiro. Revista Brasileira de Ciências Sociais, São Paulo, v. 18, n. 52, p. 35-54, 2003.

SALLUM JR., Brasílio. Crise, democratização e liberalização no Brasil. In: SALLUM JR., Brasílio (org.). Brasil e Argentina hoje: política e economia. Bauru: EDUSC, 2004. p. 20-53.

SEDGWICK, Mark. Introdução. In: SEDGWICK, Mark (org.). Key Thinkers of the Radical Right - Behind the New Threat to Liberal Democracy. Nova Iorque: Oxford University Press, 2019. p. xiii-xxvi.

SILVA, Ivan Henrique de Mattos e. O Estado pós-neoliberal e os Programas de Transferência Condicionada de Renda no Brasil e na Argentina: ruptura ou continuidade? São Carlos, 2018. 204 f. Tese (Doutorado em Ciência Política) - Departamento de Ciências Sociais, Universidade Federal de São Carlos, São Carlos, 2018.

SILVA, Ivan Henrique de Mattos e. "Liberal na economia e conservador nos costumes": uma totalidade dialética. Revista Brasileira de Ciências Sociais, São Paulo, v. 36, n. 107, p. 1-19, 2021.

SINGER, André. Brasil, junho de 2013: classes e ideologias cruzadas. Novos Estudos CEBRAP, São Paulo, n. 97, p. 23-40, 2013.

SOLA, Lourdes; KUGELMAS, Eduardo. Statecraft, instabilidade econômica e incerteza política: o Brasil em perspectiva comparada. In: DINIZ, Eli (org.). Anais do Seminário Internacional: $O$ desafio da democracia na América Latina. Rio de Janeiro: luperj, 1996. p. 398-414.

SOLANO, Esther. Apresentação. In: SOLANO, Esther (org.). 0 ódio como política: a reinvenção das direitas no Brasil. São Paulo: Boitempo Editorial, 2018. p. 15-20.

SOUZA, Jessé. A elite do atraso: da escravidão à Lava-Jato. Rio de Janeiro: Leya, 2017. 
Da Nova República à nova direita: o bolsonarismo como sintoma mórbido

STEPAN, Alfred. Os militares na política - as mudanças de padrões na vida brasileira. Tradução de Italo Tronca. Rio de Janeiro: Editora Artenova, 1975.

TATAGIBA, Luciana. Desdemocratização, ascensão da extrema direita e repertórios de ação coletiva. In: AVRITZER, Leonardo; KERCHE, Fábio; MARONA, Marjorie (org.). Governo Bolsonaro: retrocesso democrático e degradação política. Belo Horizonte: Autêntica, 2021. p. 441-452.

TEITELBAUM, Benjamin. Daniel Friberg and Metapolitics in Action. In: SEDGWICK, Mark (org.). Key Thinkers of the Radical Right - Behind the New Threat to Liberal Democracy. Nova Iorque: Oxford University Press, 2019. p. 259-276.

TEITELBAUM, Benjamin. War for Eternity - Inside Bannon's farright circle of global power brokers. Nova lorque: Dey Street Brooks, 2020.

TONELO, luri. Uma nova reestruturação produtiva pós-crise de 2008? In: ANTUNES, Ricardo (org.). Uberização, trabalho digital e Indústria 4.0. São Paulo: Boitempo Editorial, 2020. p. 139-148.

TSEBELIS, George. Veto players: How political institutions work. Princeton: Princeton University Press, 2002.

WEBER, Max. A ética protestante e o "espírito" do capitalismo. Tradução de José Marcos Mariani de Macedo. São Paulo: Companhia das Letras, 2004.

WEBER, Max. A objetividade do conhecimento na ciência social e na ciência política. In: WEBER, Max. Metodologia das Ciências Sociais, vol. 1. São Paulo: Editora da Unicamp, 1992. p. 13-107. WERNECK VIANNA, Luiz; BURGOS, Marcelo Baumann; SALLES, Paula Martins. Dezessete anos de judicialização da política. Tempo Social, São Paulo, v. 19, n. 2, p. 39-85, 2007. 